\title{
Effect of phytosterols and inulin-enriched soymilk on LDL-cholesterol in Thai subjects: a double-blinded randomized controlled trial
}

Noppadol Kietsiriroje ${ }^{1 *}$, Jirateep Kwankaew ${ }^{1,2}$, Sunita Kitpakornsanti ${ }^{1,3}$ and Rattana Leelawattana ${ }^{1}$

\begin{abstract}
Background: Hypercholesterolemia, particularly high LDL-c and non-HDL-c levels, is a traditional risk for cardiovascular disease. Ingestion of diets containing phytosterols and inulin can reduce plasma LDL-c and triglyceride levels, respectively. Phytosterols and inulin-enriched soymilk may be an alternative for a supplemental diet to improve both $\mathrm{LDL}-\mathrm{C}$ and non-HDL-c to reduce the risk of cardiovascular disease.

Methods: Two hundred and forty subjects who were 18 years old or older and had a baseline LDL-c of $130 \mathrm{mg} / \mathrm{dl}$ or higher were enrolled into the double-blinded randomized controlled trial study. Subjects were randomly assigned into the study group that received $2 \mathrm{~g} /$ day of phytosterols and $10 \mathrm{~g} /$ day of inulin-enriched soymilk or into the control group that received standard soymilk. The lipid profile was measured every 2 weeks for 8 weeks. Primary outcomes were 1) to determine the LDL-c reduction after consumption of phytosterols and inulin-enriched soymilk for 8 weeks and 2) to compare the difference of the LDL-c levels between the study and control groups. The secondary outcomes were to compare the difference of TC, TG and HDL-c between the study and control groups.

Results: At the end of the study, the median LDL-c levels decreased significantly from $165(132,254) \mathrm{mg} / \mathrm{dl}$ to 150 $(105,263) \mathrm{mg} / \mathrm{dl}$ in the study group $(p<0.001)$ and from $165(130,243) \mathrm{mg} / \mathrm{dl}$ to $159(89,277) \mathrm{mg} / \mathrm{dl}$ in the control group $(p=0.014)$. The LDL-c reduction was significantly better in the study group $(-10.03 \%,(-37.07,36.00)$ vs $-1.31 \%$ $(-53.40,89.73), p<0.001)$. TC also reduced significantly by $6.60 \%$ in the study group while it reduced only by $1.76 \%$ in the control group $(p<0.001)$. There were no statistical differences in TG and HDL-c levels between both study groups. The adverse events in the study group and the control groups were not different (RR 1.33 [0.871-2.030, $95 \%$ Cl]).

Conclusion: Daily consumption of soymilk containing $2 \mathrm{~g}$ of phytosterols and $10 \mathrm{~g}$ of inulin reduced TC and LDL-C better than standard soymilk. It had no effect on TG and HDL-c levels compared to standard soymilk. Both soymilk products were comparably safe.
\end{abstract}

Trial registration: Thai Clinical Trial Registry: TCTR20150417001 date: April 17, 2015

Keywords: Phytosterols, Inulin, LDL-C, Lipid profile

\footnotetext{
* Correspondence: Knoppado@medicine.psu.ac.th

'Division of Endocrinology and Metabolism, Department of Internal

Medicine, Faculty of Medicine, Prince of Songkla University, 15 Kanjanavanish

Rd, Hat Yai, Songkhla 90110, Thailand

Full list of author information is available at the end of the article
}

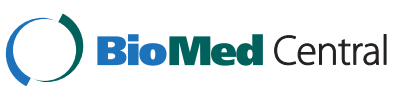

(C) 2015 Kietsiriroje et al. Open Access This article is distributed under the terms of the Creative Commons Attribution 4.0 International License (http://creativecommons.org/licenses/by/4.0/), which permits unrestricted use, distribution, and reproduction in any medium, provided you give appropriate credit to the original author(s) and the source, provide a link to the Creative Commons license, and indicate if changes were made. The Creative Commons Public Domain Dedication waiver (http://creativecommons.org/publicdomain/zero/1.0/) applies to the data made available in this article, unless otherwise stated. 


\section{Background}

Hypercholesterolemia, particularly low-density lipoprotein cholesterol (LDL-c), is an important risk factor for cardiovascular disease. In addition to lipid-lowering agents, recent guidelines have suggested to intake a diet which includes $2 \mathrm{~g} /$ day of phytosterols including plant sterol and plant stanol to decrease LDL-c [1-4]. Phytosterols are sterols from plants which are unable to be synthesized by the human body, thus it is necessary to add them (e.g., nuts, legumes and seeds) to the diet [5]. The structure of phytosterols is similar to cholesterol [6] (Fig. 1) and they compete with the cholesterol to incorporate into mixed micelles formation inside the intestinal lumen. Finally micelles containing phytosterols are absorbed into the enterocytes through the NiemannPick C1-like 1 (NPC1L1) dependent pathway but phytosterols will efflux back into the intestinal lumen through heterodimeric sterol transporter ABCG5/ ABCG8 [ATP-binding cassette $(\mathrm{ABC})$ transporters $\mathrm{G} 5$ and G8] [7]. With this process, the ingestion of $2-2.5 \mathrm{~g} /$ day of phytosterols in the diet can reduce plasma LDL-c levels by $8-15 \%$ in patients with or without a concomitant statin $[8,9]$. From a meta-analysis, the LDL-c reduction effect depended on the amount of phytosterols ingested and the effect was sustained after the intake of $2 \mathrm{~g}$ or more per day of phytosterols [10]. Phytosterols have a neutral effect on the triglyceride (TG) or high- density lipoprotein cholesterol (HDL-c) levels in plasma [11]. There is a lack of data on phytosterols content in the Thai diet which should be lower than the western diet that usually contains $150-450 \mathrm{mg}$ of phytosterols per day; however, the total amount of phytosterols in the western diet is inadequate according to recent guideline recommendations. Phytosterols-enriched soymilk is an alternative method to increase the total phytosterols intake to meet the adequate amount recommended in the guidelines.

A relationship between the TG level and the incidence of cardiovascular disease (CVD) is still controversial but there was evidence of stronger links between hypertriglyceridemia and CVD risk in people with lower levels of HDL-c and LDL-c $[12,13]$ and with type 2 diabetes mellitus (T2DM) [14]. The National Lipid Association (NLA) Expert Panel recommendations also indicated that the normal level of serum TG was less than $150 \mathrm{mg} / \mathrm{dl}[15]$.

Inulin-type fructans, which are nondigestible carbohydrates, are capable of decreasing TGs by many mechanisms including 1) decreased hepatic lipogenesis, 2) increased muscle lipoprotein lipase activity and 3) increased short chain fatty acids by bacterial fermentation of carbohydrates which is also capable of inhibiting TG synthesis [16]. In a human study, adding $10 \mathrm{~g}$ of highperformance inulin into a moderately high-carbohydrate,<smiles>CC(C)CCCC(C)C1CCC2C3CC=C4CC(O)CCC4(C)C3CCC12C</smiles><smiles>CCC(CCC(C)C(CC)CCC(C)C1CCC2C3CCC4CC(O)CCC4(C)C3CCC12C)C(C)CCC(C)C1CCC2C3CC=C4CC(O)CCC4(C)C3CCC12C</smiles>

Fig. 1 Structure of phytosterols (sitosterol and sitostanol) 
low-fat diet in 8 healthy subjects decreased the TG level by inhibiting hepatic lipogenesis [17]. A meta-analysis that included 15 studies concluded that the intake of inulin-type fructans (average amount of inulin was $14.2 \mathrm{~g} /$ day [range 4-32]) was associated with a significant decrease in the TG level by $15.05 \mathrm{mg} / \mathrm{dl}$ [18]. However, the triglyceride-lowering effect of inulin is inconsistent among trials and is still inconclusive [16, 18, 19]. Thus, the phytosterols and inulin-enriched soymilk may be an alternative to supplement the diet to improve both LDL-c and non-HDL-c to reduce the risk of cardiovascular disease.

Much data confirmed the effects of phytosterols or inulin-enriched products on the lipid profile in many ethnicities but this effect among the Thai population lacks data. This research aims to confirm the effect of phytosterols and inulin on the lipid profile among the Thai population after ingesting phytosterols and inulinenriched soymilk for 8 weeks.

\section{Methods}

\section{Study design}

This was a double-blinded, randomized-controlled trial that enrolled 240 adult volunteers from the outpatient department and the Endocrinology and Metabolism Unit of Songklanagarind Hospital at Prince of Songkla University from 28 May 2013 to 5 June 2014. The inclusion criteria were 1) subjects who were 18 years old or older and 2) subjects whose LDL-c levels were $130 \mathrm{mg} / \mathrm{dl}$ or higher. None of patients were taking statins. The exclusion criteria were 1) subjects who had established cardiovascular disease, 2) subjects who had any type of diabetes mellitus, 3) subjects who had gastrointestinal dysmotility, 4) subjects who had abnormal gastrointestinal digestion or absorption, 5) subjects who had an allergy to soymilk and 6) subjects who had secondary hyperlipidemia such as hypothyroidism, nephrotic syndrome or hepatic disease. Withdrawal or termination criteria were 1) subject's intention to withdraw, 2) subjects loss to follow-up, 3) elevated transaminase enzymes $>3$ fold of the upper normal limits, 4) reduced glomerular filtration rate $\geq 1$ stage by the Kidney Disease Outcomes Quality Initiative criteria, 5) subjects unable to tolerate adverse events from soymilk products and 6) compliance of subjects less than $80 \%$ per visit. This study was approved by the Songklanagarind Hospital ethics committee. Written informed consents were obtained before screening and randomization.

The study subjects were randomly assigned by a thirdparty into the study group which received phytosterols and inulin-enriched soymilk or into the control group which received standard soymilk. The simple random sampling was used to generate a number sequence by the sponsor and the number sequence was given for randomization with an allocation ratio of 1:1. The intervention assignments were concealed to both subjects and clinical staff before randomization. All subjects were given instructions to drink soymilk products twice daily, once in the morning and once in the evening. Subjects who consumed soymilk products less than $80 \%$ were determined as non-compliance.

\section{Soymilk products}

The phytosterols and inulin-enriched soymilk (UHT SOY MILK WITH PHYTOSTEROL; DNA ${ }^{\circ}$, Thai FDA food registration number 60-1-05841-2-0089) and standard soymilk in this study were supplied by Dairy Plus Company Limited. A serving unit of both soymilk products contained $180 \mathrm{ml}$ of soymilk, $4.5 \mathrm{~g}$ of fat, $5 \mathrm{~g}$ of protein and $12 \mathrm{~g}$ of carbohydrate. In addition, a serving unit of the phytosterols and inulin-enriched soymilk contained $1 \mathrm{~g}$ of phytosterols and $5 \mathrm{~g}$ of inulin. The components of the soymilk products are shown in Tables 1 and 2 .

\section{Data collection at baseline before randomization}

Subjects who met the inclusion criteria at the screening visit proceeded to history taking and blood pressure and anthropometry measurements that included body mass index (BMI), waist circumference (WC) and hip circumference $(\mathrm{HC})$ by well-trained personnel. Blood samples for laboratory testing were drawn after fasting for $12 \mathrm{~h}$ at screening. All subjects were requested by a nurse to record their eating and exercise behaviors through a 7 day diet and physical activity questionnaire for 1 week before randomization (week 0).

\section{Follow-up data after randomization}

At randomization, all subjects were given guidance to change their eating and exercise behaviors and record them in the 7-day diet and physical activity questionnaire. All subjects had to follow-up at the clinic every 2 weeks for 8 weeks. At each follow-up, all subjects were interviewed for adverse events and underwent a related physical examination. The blood pressure and anthropometry measurements were also taken every visit. Blood samples for biochemistry testing were drawn after fasting for $12 \mathrm{~h}$ at weeks 2, 4, 6 and 8 . The $75 \mathrm{~g}$ oral glucose tolerance tests were conducted at the randomization time (week 0 ).

\section{Anthropometry measurements}

Well-trained personnel measured the WC and HC. The waist circumference was measured at midline between the lower ribs and the iliac crest during expiration. The hip circumference was measured at the widest part of the hip. The BMI was computed from body weight and height and the waist-hip ratio was computed from the WC and HC measurements. 
Table 1 Macronutrient composition of both soymilk products

\begin{tabular}{|c|c|c|}
\hline \multirow[t]{2}{*}{ Component } & \multicolumn{2}{|l|}{ Percentage (\%) } \\
\hline & $\begin{array}{l}\text { Phytosterols and inulin-enriched } \\
\text { soymilk }\end{array}$ & $\begin{array}{l}\text { Standard } \\
\text { soymilk }\end{array}$ \\
\hline - Soy milk & 93.3 & 93.3 \\
\hline - Inulin & 3 & 0 \\
\hline - Sugar & 2.5 & 2.5 \\
\hline - Calcium & 0.7 & 0.7 \\
\hline - Oat flour & 0.03 & 0.03 \\
\hline - Vitamin complex & 0.03 & 0.03 \\
\hline - Green Tea extract & 0.015 & 0.015 \\
\hline - Wheat Grass extract & 0.0005 & 0.0005 \\
\hline - Phytosterols & $0.55(100 \%)$ & 0 \\
\hline o Total sterol esters & $91 \%$ & \\
\hline o Free sterols & $6 \%$ & \\
\hline
\end{tabular}

\section{Biochemistries}

Venous blood samples were drawn between 08:00 and10:00 after a 12-h fast. Serum aliquots were stored at room temperature and transported to the laboratory for testing on the same day. Fasting plasma glucose (FPG), total cholesterol (TC), TG, HDL-c and LDL-c levels were measured by enzymatic in vitro assay for direct determination using a MODULAR P800 analyzer. The interassay coefficients of variation of the fasting plasma glucose, total cholesterol, triglyceride, HDL-c and LDL-c were 1.48$1.52 \%, 1.57-1.59 \%, 1.62-1.71 \%, 2.22-2.35 \%$ and $1.96-2.19 \%$, respectively.

\section{Adverse events}

The subjects were asked every 2 weeks about adverse events including abdominal pain, bloating, nausea, vomiting and increased frequency of defecation or diarrhea when they visited the clinic. Transaminase enzymes

Table 2 Sterol composition of UHT SOY MILK WITH PHYTOSTEROL; DNA ${ }^{\oplus}$

\begin{tabular}{ll}
\hline Sterol composition ${ }^{\text {a }}$ (as free sterols) & By GC, rel. area (\%) \\
\hline Cholesterol & $0.0-2.0$ \\
Brassicasterol & $2.0-6.0$ \\
Campesterol & $20.0-29.0$ \\
Campestanol & $0.0-6.0$ \\
Stigmasterol & $12.0-23.0$ \\
Beta-sitosterol & $42.0-55.0$ \\
Sitostanol & $0.0-2.5$ \\
D5-Avenasterol & $0.0-4.0$ \\
D7-stigmastenol & $0.0-2.0$ \\
D7-Avenasterol & $0.0-2.0$ \\
Other sterols & $0.0-5.0$ \\
\hline
\end{tabular}

a according Food Chemical Codex Monograph and renal function tests were performed every 2 weeks to monitor for any serious adverse events. A serious adverse event was defined by an adverse event which led to withdrawal or termination of the patient from the study.

\section{Outcomes}

Primary outcomes were 1) to compare the LDL-c levels of subjects before and after consumption of the phytosterols and inulin-enriched soymilk for 8 weeks and 2) to compare the LDL-c levels in subjects who consumed the phytosterols and inulin-enriched soymilk to the subjects who consumed standard soymilk. Secondary outcomes were to compare the TC, TG and HDL-c levels in subjects who consumed phytosterols and inulin-enriched soymilk to the subjects who consumed standard soymilk. The potential confounders on the change in the lipid profile included age, sex, BMI and hypertension.

\section{Sample size calculation}

The sample size of the study was calculated using the formula illustrated below.

$$
\begin{aligned}
\mathrm{n} \text { (pairs) } & =2\left[\left(\mathrm{Z}_{\alpha}+\mathrm{Z}_{\beta}\right) \mathrm{SD}\right]^{2} / \mathrm{D}^{2} \\
& =2[(1.96+0.84) 26.3]^{2} / 95.0625 \\
& =114 \text { pairs } \\
\text { 2-tailed study } \alpha & =0.05, \mathrm{Z}_{\alpha}=1.96, \beta=0.20, \mathrm{Z}_{\beta} \\
& =0.84
\end{aligned}
$$

To calculate all variables in the formula, we used data referring to the Weidner, C. et al. study [20]. The mean LDL-c level in subjects who consumed phytosterols and inulin-enriched soymilk for 8 weeks decreased from 164 $\pm 25 \mathrm{mg} / \mathrm{dl}$ to $152.9 \pm 24 \mathrm{mg} / \mathrm{dl}$ while the mean LDL-c level in subjects who consumed standard soymilk decreased from $160 \pm 25 \mathrm{mg} / \mathrm{dl}$ to $159.5 \pm 28.5 \mathrm{mg} / \mathrm{dl}$. The mean difference of the LDL-c between the groups was $9.75 \mathrm{mg} / \mathrm{dl}$.

$$
\begin{aligned}
\mathrm{D}^{2} & =(9.75)^{2}=95.0625 \\
\mathrm{SD} & =\sqrt{\text { pooled variance }} \\
= & \sqrt{\frac{\left[\left(\mathrm{n}_{1}-1\right) S D_{1}^{2}+\left(\mathrm{n}_{2}-1\right) S D_{2}^{2}\right]}{\mathrm{n}_{1}+\mathrm{n}_{2}-2}} \\
= & \sqrt{\frac{19494+13824}{48}} \\
= & 26.3 \mathrm{mg} / \mathrm{dl}
\end{aligned}
$$

The dropout rate was set to be at least $5 \%$, thus the total number of subjects in this study was calculated to be approximately 240 subjects (120 subjects in each arm) 


\section{Statistical analysis}

Descriptive data were showed in mean, median, standard deviation (SD) and range (min,max). The likelihood ratio test or Fisher's exact test was used to identify differences between the baseline characteristics which were categorical data and the Mann-Whitney $U$ test was used in case of continuous data. The statistical analysis to determine the difference of LDL-C and other lipids between the study groups used the Mann-Whitney $U$ test. The statistical analysis to determine the difference of LDL-C between pre- and post-intervention in each study group used the Wilcoxon signed-rank test. Multiple linear regression was used to adjust potential confounders including age, sex, BMI and hypertension, using the baseline LDL-c value as a covariate. A change-in-estimation criterion with a cut-off of $10 \%$ was used to identify the confounders [21]. Pearson correlation was used to determine the correlation between baseline LDL-c and percent LDL-c change. Pearson Chi-square was used to determine the relative risk of adverse events between groups. A $p$-value $<0.05$ indicated statistical significance. $\mathrm{R}-3.1 .2$ for Windows was used for the data analyses.

\section{Results}

Two hundred and seventy-three volunteers were screened. The number of subjects who met the inclusion criteria and enrolled into the study was 240. The enrolled subjects were 1:1 randomized into the study group or the control group which put 120 subjects in each group. Thirteen subjects $(5.42 \%)$ withdrew from the study; 4 subjects had serious adverse events, 5 subjects were loss to follow-up, 1 subject was noncompliant and 3 subjects requested withdrawal from the study because of pregnancy, anterior cruciate ligament surgery and the inconvenience of drinking a soymilk product. Two hundred and twenty-seven subjects (94.58 \%) were included into the primary outcome analysis (Fig. 2).

Demographic and baseline characteristics of the subjects are shown in Table 3. Subjects were predominantly female (85\%); $57.5 \%$ of the subjects were government employees and $19.16 \%$ of the subjects were university employees. Cardiovascular risk factors of the subjects in the study were $91.67 \%$ of the subjects never smoked, $3.75 \%$ of the subjects reported they had hypertension, $9.09 \%$ of the subjects reported dyslipidemia and $2.5 \%$ of the subjects reported a family history of cardiovascular disease. The median age of the subjects was 47.5 $(18,71)$ years old, mean BMI was $24.20 \pm 3.48 \mathrm{~kg} / \mathrm{m}^{2}$, median WC was $82.5(60,122) \mathrm{cm}$, median systolic blood pressure was $117(87,176) \mathrm{mmHg}$ and median diastolic blood pressure was $72(36,117) \mathrm{mmHg}$, median FPG was $90(71,114) \mathrm{mg} / \mathrm{dl}$ and the median LDL-c level was 165 $(130,254) \mathrm{mg} / \mathrm{dl}$. There were no differences in the demographic and baseline characteristic data between the study group and the control group except the report of dyslipidemia in the study group was higher than the control group ( $12.5 \%$ vs $4.17 \%, p=0.033)$.

At the end of the study, the median LDL-c levels decreased significantly from $165(132,254) \mathrm{mg} / \mathrm{dl}$ to 150 $(105,263) \mathrm{mg} / \mathrm{dl}$ in the study group $(p<0.001)$ and from $165(130,243) \mathrm{mg} / \mathrm{dl}$ to $159(89,277) \mathrm{mg} / \mathrm{dl}$ in the control group ( $p=0.014$ ) (Fig. 3 ). The biweekly lipid profiles in both groups are shown for comparison in Table 4 . The difference in the LDL-c levels between the groups started to show at the second week and it persisted until the end of the study $(\mathrm{p}<0.05)$. The percent LDL-c reduction in the study group was significantly greater than the control group $(-10.03 \%(-37.07,36.00 \%)$ vs $-1.31 \%$ $(-53.40,89.73 \%), p<0.001)$ (Table 5) and the LDL-c reduction efficacy of both soymilk products was also independent to potential confounders including age, sex, BMI and hypertension after they were adjusted (Additional file 1). Subgroup analysis showed trends of LDL-c reduction were not different between subgroups defined by 1) with or without hypertension, 2) male or female, 3) normal weight or over weight (for the Asian population) and 4) younger or older than 50 years (Fig. 4).

Pearson correlation showed a small but significant correlation between the baseline LDL-c and percent LDL-C change in the study group $(r=-0.23, p$-value $=0.007)$. Linear regression analysis was used to determine the LDL-c reduction effect of phytosterols and inulin enriched soymilk and found that for every $1 \mathrm{mg} / \mathrm{dl}$ increment of baseline LDL-c, the LDL-c reduction increased by $0.11 \%$ (coefficient $=-0.11, p$-value $=0.014)$. In the control group, although there was also a small but significant correlation found between the baseline LDL-c and percent LDL-c change $(r=-0.27$, $\mathrm{p}$-value $=0.002)$, it should be noted that the LDL-reduction effect of standard soymilk was seen only if the baseline LDL-c was over $153 \mathrm{mg} / \mathrm{dl}$ while the standard soymilk would increase LDL-c level among the subjects with lower baseline LDL-c. This pattern is explained by the 'regression to the mean' phenomenon (Fig. 5).

The phytosterols and inulin-enriched soymilk also significantly reduced the TC level compared to standard soymilk. The percentage of TC reduction in the study group was $6.60 \%$ while it was only $1.76 \%$ in the control group $(p<0.001)$. The TG level did not significantly change in either group which increased by $0.96 \%$ in the study group and $0.50 \%$ in the control group $(p=0.96)$. The HDL-c level also did not significantly change in either group which increased by $1.53 \%$ in the study group and unchanged in the control group $(p=0.70)$ (Table 5).

In both study and control groups, the FPG levels were similar to the baseline levels during the entire study period and they were not different between the groups 


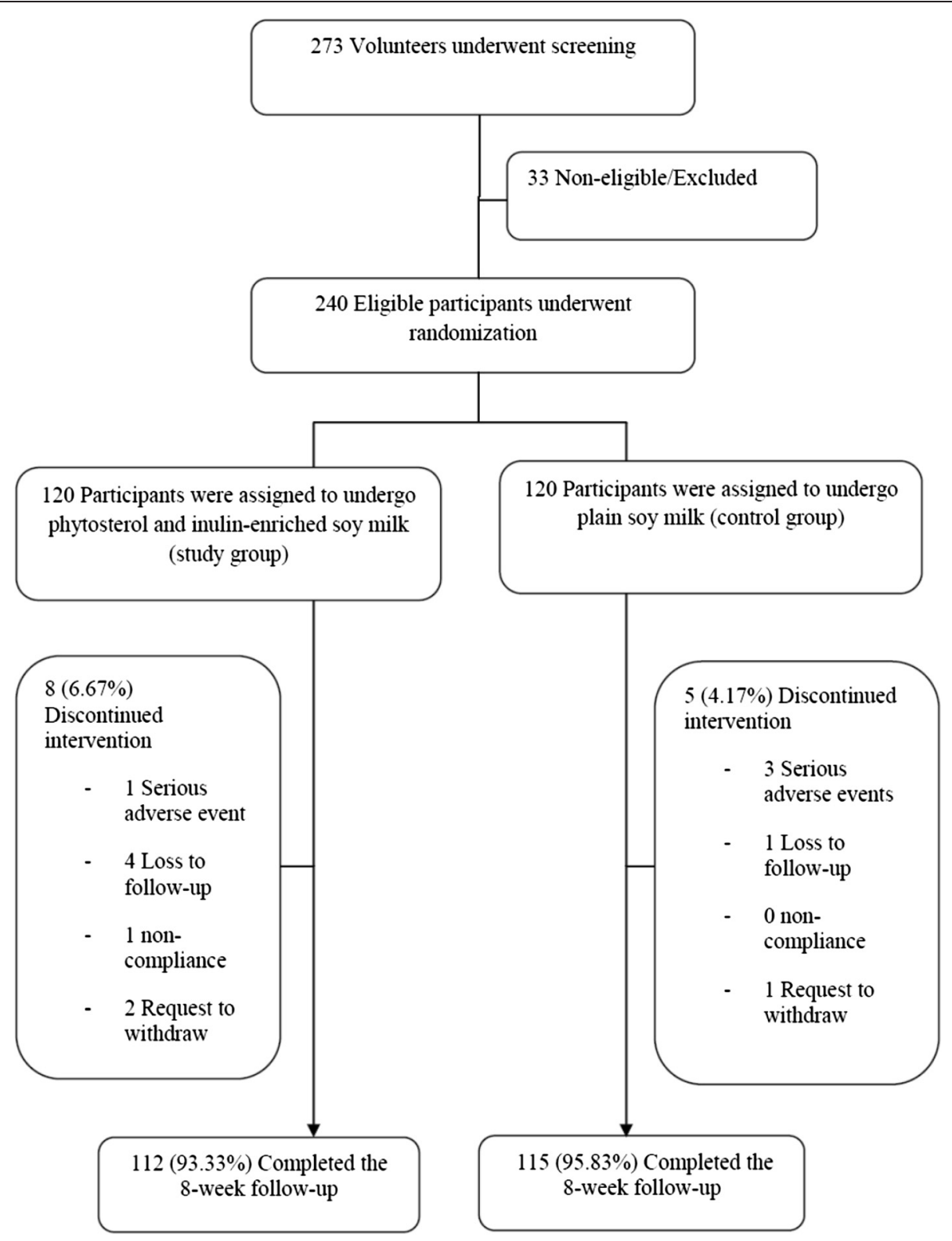

Fig. 2 CONSORT flow diagram

(Additional file 2). Thirty-one percent of subjects in the study group had adverse events while $23.3 \%$ of subjects in the control group had adverse events (relative risk = $1.33[0.87-2.03,95 \% \mathrm{CI}])$. There were four serious adverse events that occurred in the study included one severe diarrhea in the study group and another in the control group, one severe bloating in the control group and one hepatitis (defined by transaminase enzymes that were 3 fold higher than the upper normal limits) in the control group. The most common adverse events was bloating (overall $71.56 \%$ ) which seemed to be more common in the study group $(76.92 \%)$ than the control group $(64.72 \%)$ and it seemed to more persistent in the study group (additional file 3). The adverse events in each group are shown in Table 6.

\section{Discussion}

The present study confirmed LDL-c reduction with $1 \mathrm{~g}$ phytosterols and $5 \mathrm{~g}$ inulin-enriched soymilk twice daily among statin-naïve, mild-to-moderate hypercholesterolemia subjects. The absolute LDL-c reduction efficacy of $2 \mathrm{~g} /$ day of phytosterols and $10 \mathrm{~g} /$ day of inulin was $8.72 \%$ which was comparable to previous studies. Kriengsinyos W. et al. reported an LDL-c reduction efficacy of $2 \mathrm{~g}$ stanol-containing soymilk once a day and postprandially for 6 weeks that was an absolute $8.9 \%$ 
Table 3 Comparison of baseline characteristics, biochemical tests and lipid profiles between groups $(n=240)$

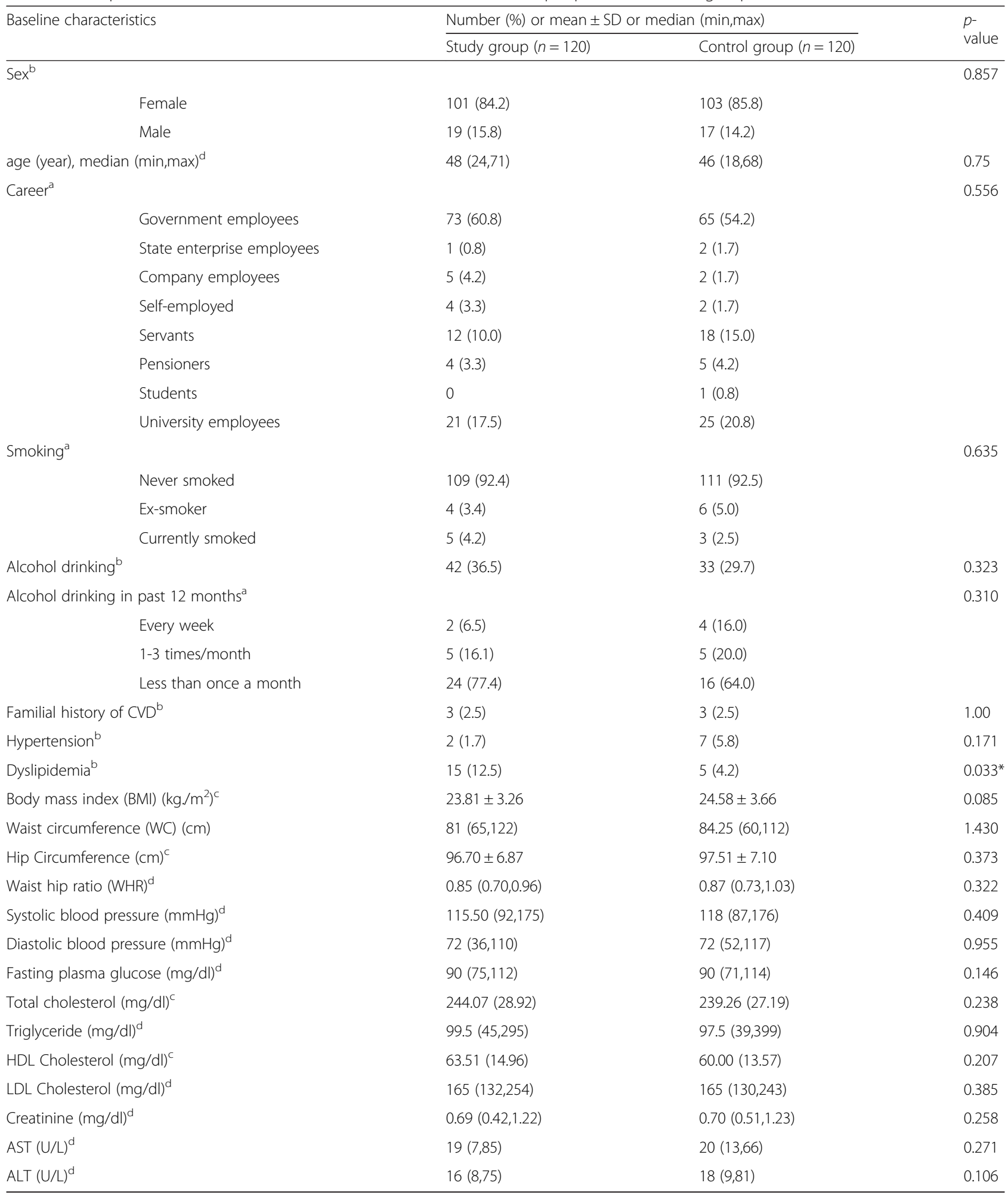

${ }^{*} p<.05, \mathrm{a}=$ likelihood ratio test, $\mathrm{b}=$ Fisher's exact test, $\mathrm{c}=$ independent $t$-test, $\mathrm{d}=$ Mann-Whitney $U$ test

[22]. The LDL-c reduction efficacy was comparable to either once daily or twice daily administration as long as the total dose of phytosterols was $2 \mathrm{~g}$ per day. Two grams daily of phytosterols reduced LDL-c level by 8$14 \%$, which depended on the initial baseline LDL-c of the subjects. At a higher baseline LDL-c, the benefits of 


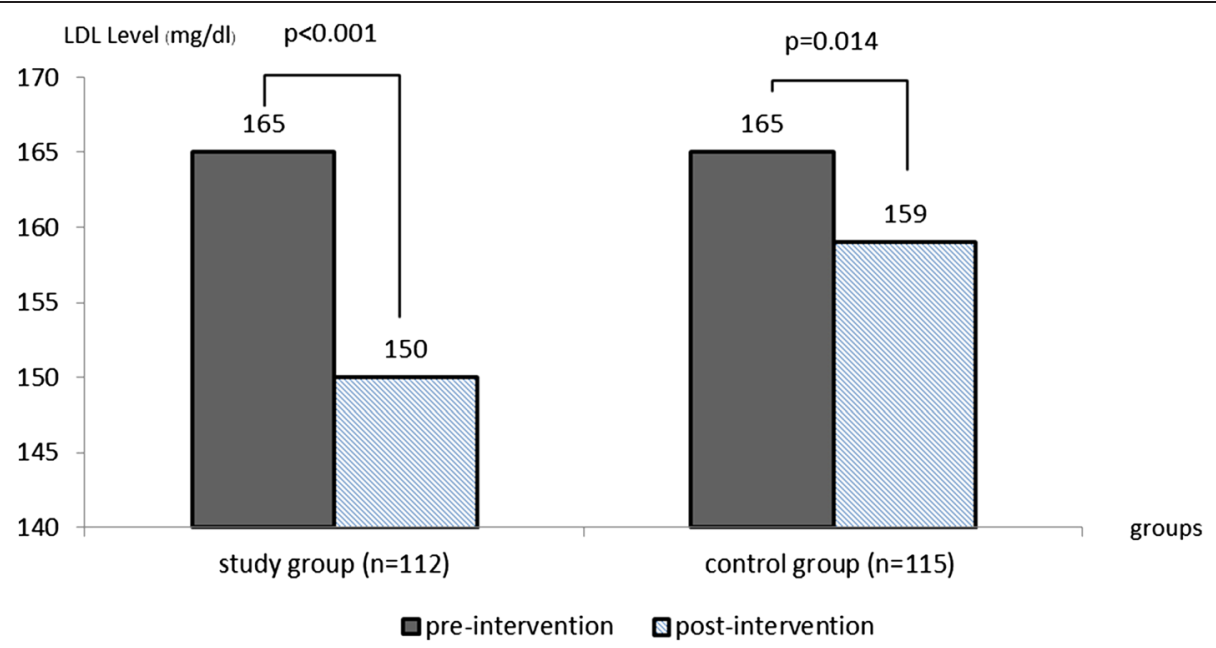

Fig. 3 Pre- and post-intervention LDL-c levels between the study and control groups at weeks 0 and 8 by Wilcoxon signed-rank test $(n=227)$

phytosterols were apparently observed [23, 24]. In the present study, LDL-c reduction efficacy of phytosterols and inulin enriched soymilk had a small but significant correlation to baseline LDL-c. Every $1 \mathrm{mg} / \mathrm{dl}$ increment of baseline LDL-c affected the LDL-c reduction by an increase of $0.11 \%$, while a similar correlation also existed in the standard soymilk group but it seemed to be a 'regression to the mean' phenomenon. The LDL-c level was significantly lower in the study group from the second week and it was constantly lower in the study group throughout the study period. The action of phytosterols to inhibit intestinal cholesterol absorption seemed to occur

Table 4 Comparison of total cholesterol, triglyceride, HDL-C and LDL-c between the study and control groups at weeks 0, 2, 4, 6 and $8(n=240)$

\begin{tabular}{|c|c|c|c|c|}
\hline & & \multicolumn{2}{|l|}{ Median (min,max) } & \multirow[t]{2}{*}{$p$-value } \\
\hline & & Study group $(n=120)$ & Control group $(n=120)$ & \\
\hline \multirow[t]{5}{*}{ Total cholesterol } & Week 0 & $239.5(191,368)$ & $235(178,317)$ & 0.238 \\
\hline & Week 2 & $223(162,336)$ & $235(167,305)$ & 0.065 \\
\hline & Week 4 & $228(164,319)$ & $229(166,316)$ & 0.203 \\
\hline & Week 6 & $225(118,308)$ & $234(151,309)$ & $0.011^{*}$ \\
\hline & Week 8 & $223.50(173,335)$ & $232(147,319)$ & 0.144 \\
\hline \multirow[t]{5}{*}{ Triglyceride } & Week 0 & $99.5(45,295)$ & $97.5(39,399)$ & 0.904 \\
\hline & Week 2 & $94.0(41,309)$ & $99.0(30,364)$ & 0.782 \\
\hline & Week 4 & $92(34,330)$ & $100(30,423)$ & 0.438 \\
\hline & Week 6 & $94.5(41,336)$ & $97(41,481)$ & 0.512 \\
\hline & Week 8 & $95.5(38,277)$ & $107(41,304)$ & 0.494 \\
\hline \multirow[t]{5}{*}{ HDL cholesterol } & Week 0 & $61(34,109)$ & $59(21,97)$ & 0.207 \\
\hline & Week 2 & $60(31,99)$ & $58(32,93)$ & 0.344 \\
\hline & Week 4 & $62(36,102)$ & $58(28,92)$ & 0.131 \\
\hline & Week 6 & $63(33,96)$ & $60(29,96)$ & 0.082 \\
\hline & Week 8 & $60.5(35,103)$ & $57(27,97)$ & 0.174 \\
\hline \multirow[t]{5}{*}{ LDL cholesterol } & Week 0 & $165(132,254)$ & $165(130,243)$ & 0.385 \\
\hline & Week 2 & $153(95,256)$ & $165(91,235)$ & $0.032^{*}$ \\
\hline & Week 4 & $150.50(91,234)$ & $160(97,244)$ & $0.024^{*}$ \\
\hline & Week 6 & $151(96,223)$ & $163(93,234)$ & $0.003^{* *}$ \\
\hline & Week 8 & $150(105,263)$ & $159(89,277)$ & $0.009^{* *}$ \\
\hline
\end{tabular}


Table 5 Comparison of percentage changes in the total cholesterol, triglyceride, HDL-c and LDL-c levels between the study and control groups at week $8(n=240)$

\begin{tabular}{llll}
\hline & Median (min,max) & & $p$-value* \\
\cline { 2 - 3 } & Study group $(n=120)$ & Control group $(n=120)$ & $<0.001$ \\
\hline Total cholesterol & $-6.60(-32.35,35.00)$ & $-1.76(-41.43,34.35)$ & 0.96 \\
Triglyceride & $0.96(-41.14,128.93)$ & $0.50(-69.42,176.40)$ & 0.70 \\
HDL Cholesterol & $1.53(-53.85,24.59)$ & $0(-25.42,57.14)$ & $<0.001$ \\
LDL Cholesterol & $-10.03(-37.07,36.00)$ & $-1.31(-53.40,89.73)$ & \\
\hline
\end{tabular}

*Mann-Whitney $U$ test

instantly after consuming the phytosterols-enriched soymilk. The LDL-c level was also significantly reduced in subjects who consumed the standard soymilk but its effect was trivial. This effect probably occurred because 1) the subjects possibly changed their eating and exercise behaviors after enrollment in the study and 2) soy protein in the standard soymilk had an LDL-c reduction effect $[25,26]$.

The effect of phytosetrols may be influenced by the types of food carriers. A previous meta-analysis reported that high-fat content food carriers might have a greater effect than low-fat content food carriers [23]. One previous study demonstrated the LDL-c lowering effects of phytosterols incorporated into various food carriers, the absolute LDL-c reductions for yoghurt, hard cheese and fresh cheese were $7.7 \%, 10.9 \%$ and $8.6 \%$, respectively [27]. Many reports demonstrated the LDL-c lowering effects of phytosterols incorporated into low-fat content food carriers such as low-fat yoghurt [28, 29], milk [29], yoghurt drinks [30] and orange juice [31], which varied from $6.4 \%$ to $15.9 \%$. Hence, the low-fat content food carriers were good matrixes for incorporation of phytosterols. Few studies, including the present one, reported the LDL-c lowering effects of 7-13\% of phytosterols-enriched soymilk on LDL-c which was similar to other low-fat content food carriers [20, 22, 32]. Thus, soymilk also proved to be a good matrix for incorporation of phytosterols.

LDL-c is a well-known important risk factor for cardiovascular disease while every $1 \mathrm{mg}$ of LDL-c reduction relatively decreases the risk of having a coronary event by $1 \%$ [33]. The phytosterols-enriched soymilk, which proved its LDL-c reduction effect, may have other effects to reduce the risk of cardiovascular disease; however, further investigations are required to determine the cardiovascular outcome.

High TG and low HDL-c levels are other risk factors for cardiovascular disease particularly in people with metabolic syndrome or T2DM. Due to the concern that the additional carbohydrate and free fatty acid from both soymilk products might increase the TG levels and lower the HDL-c levels, the effects of both soymilk products on TG and HDL-c levels were determined. In the

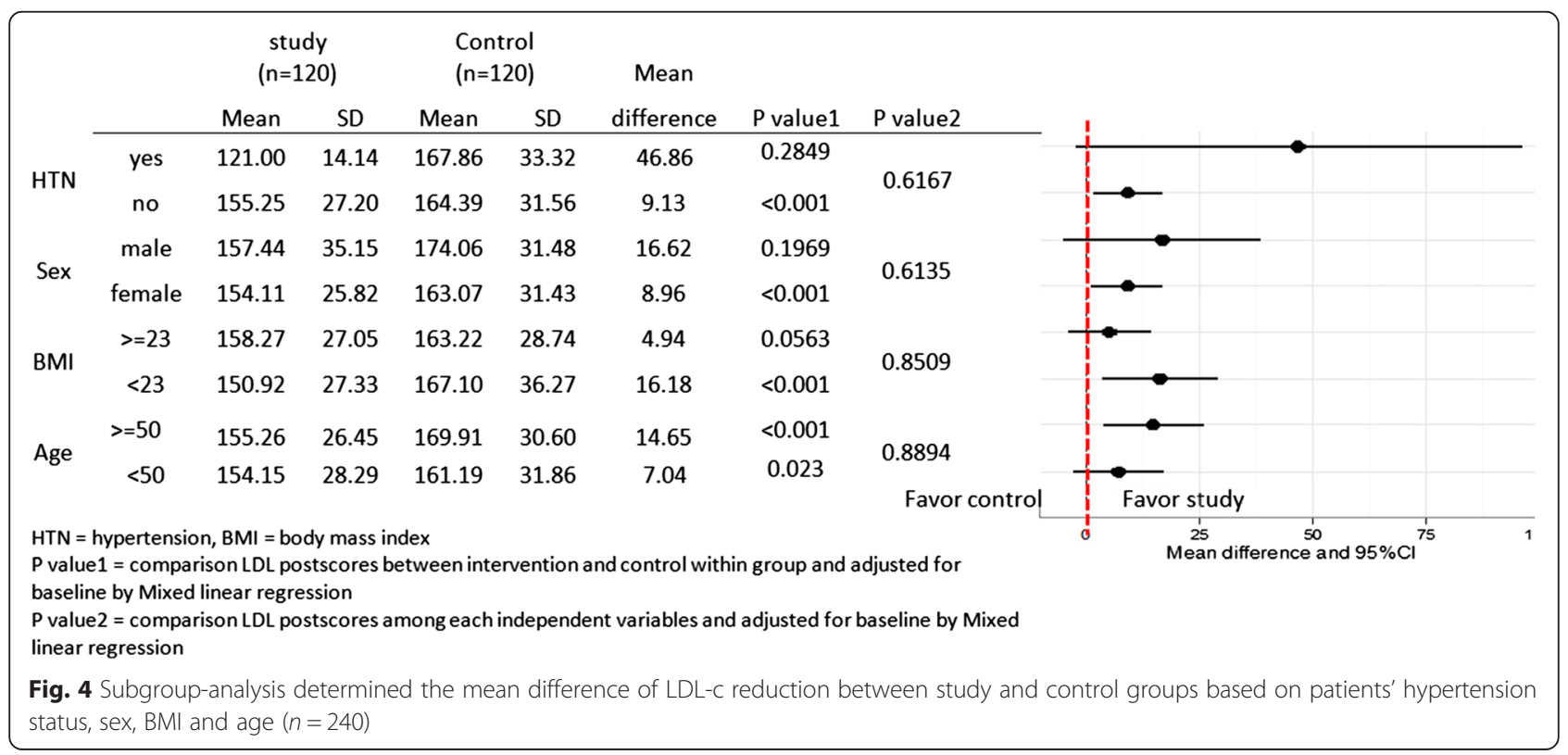



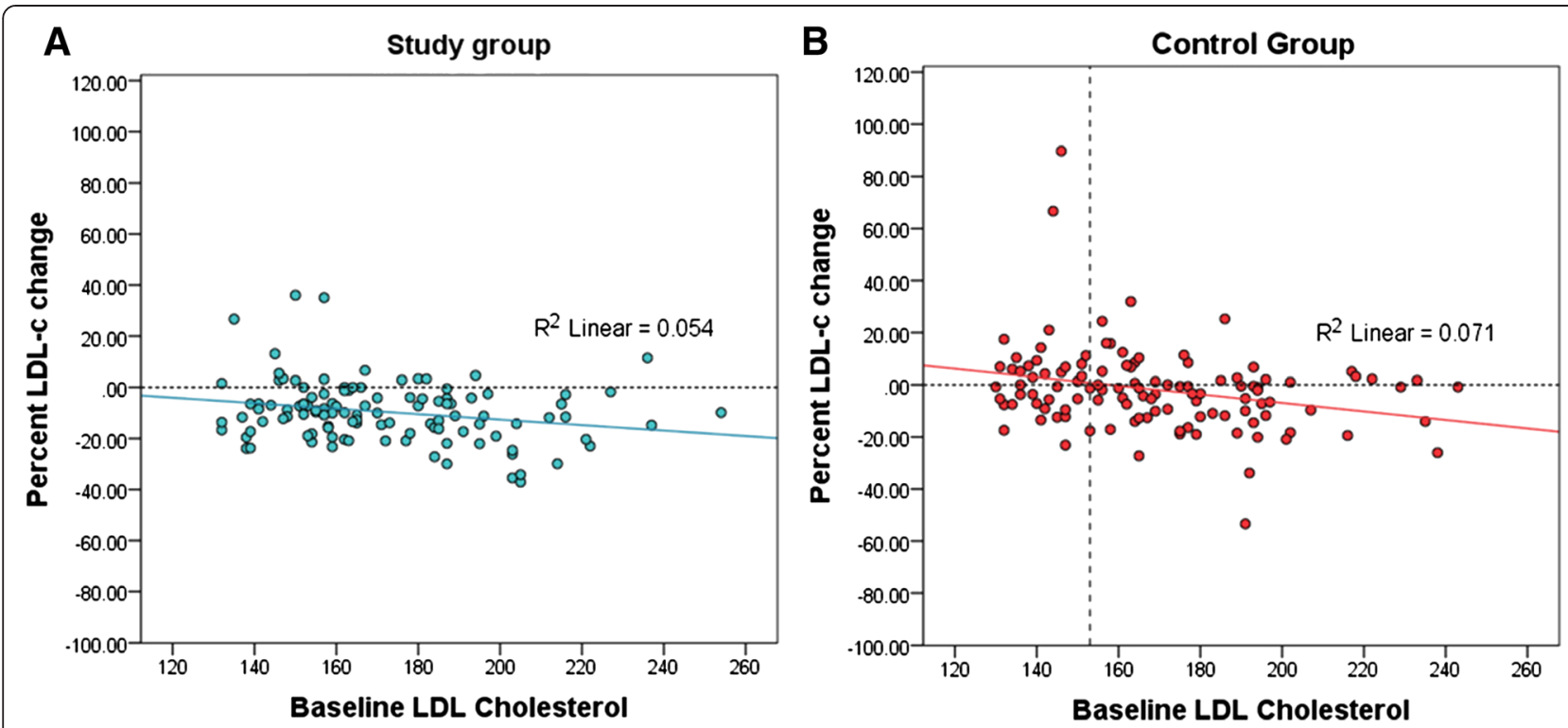

Fig. 5 Correlation between baseline LDL-c and percent LDL-c change; (a) study group $(n=115)$, (b) control group $(n=112)$

present study, the phytosterols and inulin-enriched soymilk and standard soymilk had a neutral effect on both TG and HDL-c levels which was in agreement with previous studies $[11,34]$. The ESC/EAS guideline also concluded that $2 \mathrm{~g}$ daily of phytosterols had little or no effect on TG and HDL-c levels [3]. However, it should be noted that subjects recruited into this study were metabolically lean with low TG and high HDL-c levels and subjects with T2DM were excluded from the study. Thus, we cannot imply that either soymilk product would not increase TG levels in subjects with metabolic syndrome or T2DM.

On the contrary, we expected to see a better TG level in the study group from the inulin effect but the present study could not demonstrate a positive effect from $10 \mathrm{~g} /$ day of inulin to decrease TG levels. Letexier et al. demonstrated TG reduction efficacy of $10 \mathrm{~g} /$ day of inulin

Table 6 Number of subjects having adverse events from total visits and the adverse events categorized by severity in the study and control groups

\begin{tabular}{|c|c|c|c|c|c|}
\hline & \multicolumn{3}{|l|}{ Number (\%) } & \multirow[b]{2}{*}{$\mathrm{RR}[95 \% \mathrm{Cl}]$} & \multirow[b]{2}{*}{$p$-value } \\
\hline & Study group $(n=116)^{a}$ & Control group $(n=120)$ & Total $(n=236)$ & & \\
\hline Subjects had adverse events, person & $36(31.0)$ & $28(23.3)$ & $64(27.12)$ & $1.33[0.87-2.03]$ & $0.177^{b}$ \\
\hline Actual adverse events, event & $65(100)$ & $51(100)$ & $116(100)$ & & \\
\hline \multicolumn{6}{|l|}{ Serious adverse events } \\
\hline Bloating & $0(0)$ & $1(1.96)$ & $1(0.86)$ & & \\
\hline Hepatitis & $0(0)$ & $1(1.96)$ & $1(0.86)$ & & \\
\hline Severe diarrhea & $1(1.54)$ & $1(1.96)$ & $2(1.72)$ & & \\
\hline \multicolumn{6}{|l|}{ Non-serious adverse events } \\
\hline Bloating & $50(76.92)$ & $33(64.72)$ & $83(71.56)$ & & \\
\hline Abdominal cramp & $0(0)$ & $1(1.96)$ & $1(0.86)$ & & \\
\hline Nausea & $0(0)$ & $4(7.84)$ & $4(3.45)$ & & \\
\hline Vomiting & $1(1.54)$ & $1(1.96)$ & $2(1.72)$ & & \\
\hline Increase defecation & $2(3.08)$ & $0(0)$ & $2(1.72)$ & & \\
\hline Diarrhea & $4(6.15)$ & $4(7.84)$ & $8(6.90)$ & & \\
\hline Constipation & $2(3.08)$ & $2(3.92)$ & $4(3.45)$ & & \\
\hline Other & $5(7.69)$ & $3(5.88)$ & $8(6.90)$ & & \\
\hline
\end{tabular}

a subjects loss to follow up before the week 2, 1 subject requested to withdraw due to pregnancy

${ }^{\mathrm{b}}$ Pearson Chi-square 
when it was consumed with a low-fat, high-carbohydrate (LF/HC) diet [17]. Consumption of a LF/HC diet increased TG levels in both fasting and postprandial states by elevations of VLDL and chylomicrons in both states [35]. The mechanism of an LF/HC diet to increase TG levels was decreased VLDL clearance from the blood by lipoprotein lipase rather than increased VLDL secretion or de novo lipogenesis. The decreased VLDL clearance was possibly due to competition between VLDL and chylomicron remnants on lipoprotein lipase [36]. Thus consuming inulin together with an LF/HC diet might improve TG level by inhibiting carbohydrate absorption, resulting in reduction of chylomicron remnants released by the intestine. In our study, there were no changes in the dietary pattern of a $\mathrm{LF} / \mathrm{HC}$ diet and there was no monitoring of the dietary pattern, thus the TG reduction effect of the inulin in the present study was unseen. We did not measure the apolipoprotein (Apo) B100 which reflects VLDL production and Apo B48 which reflects chylomicron assembly by the intestine, thus we did not know whether the source of TG in our subjects came from de novo lipogenesis or a decrease in VLDL clearance by competition from chylomicron remnants. The baseline TG level might be another important factor for inulin efficacy. Jackson KG et al. demonstrated the effect of $10 \mathrm{~g}$ inulin sachets add-on in water, tea, coffee, orange juice, soup, breakfast cereal or yoghurt on TG reduction and concluded that the percent TG change was correlated with the initial TG concentration, particularly in subjects in whom fasting TG levels were greater than $132.8 \mathrm{mg} / \mathrm{dl}$ [37]. Since the baseline median TG level in the present study was lower than $100 \mathrm{mg} / \mathrm{dl}$, inulin efficacy was not seen in this study group.

The phytosterols and inulin-enriched soymilk and the standard soymilk did not alter glycemic levels in either the study group or the control group (Supplementary 1). However, the present study did not include diabetic patients into the study, thus we could not determine the effect of soymilk products on glycemic level in diabetic patients.

Occurrences of adverse events in both groups were similar and usually well-tolerated. Bloating was the most common adverse effect in both of the study and control groups, which accounted for $71.56 \%$ of overall adverse events and seemed to be more common in the phytosterols and inulin-enriched soymilk group. Neither of the soymilk products contained lactose so the possible cause of bloating was soy protein intolerance. Since inulin is a non-digestible carbohydrate and its fermentation possibly causes the intestinal gas which may explain why the bloating was more common in the study group [38]. There were 4 serious adverse events, one intolerable diarrhea in the study group and 3 events in the control group that included an intolerable bloating, an intolerable diarrhea and hepatitis. Therefore, the phytosterols and inulin-enriched soymilk seemed to be as equally safe as the standard soymilk.

The strengths of the present study were 1) the subjects included in the study were randomized well as indicated by the comparable baseline characteristics in both groups, 2) the soymilk products were blinded to both subjects and investigators, 3) overall $94.58 \%$ of the data were complete and 4) all subjects enrolled into the study were statin-naïve, so the present study proved the pure effect of phytosterols. The present study also encouraged the role of phytosterols-enriched soymilk to improve the LDL-c level among people who live in an urban area.

Limitations of the present study were 1) all subjects enrolled into the study were statin-naïve, thus we could not determine additional or synergistic effect of phytosterols on those who had prior statin-use, 2) the aim of the study was to determine the short term effect on lipid profile, so the benefit on cardiovascular outcome was undetermined by the present study and 3) the homogeneity of subjects who were non-DM and metabolically lean limited the application of the study to T2DM or metabolic syndrome subjects.

\section{Conclusions}

Consumption of soymilk containing $2 \mathrm{~g}$ of phytosterols and $10 \mathrm{~g}$ of inulin reduced LDL-c and TC better than standard soymilk. The LDL-c lowering efficacy was clearly seen from the second week. The phytosterols and inulin-enriched soymilk had no effect on TG, HDL-c and glycemic levels among the non-diabetic subjects and it was as safe as the standard soymilk. The phytosterols and inulin-enriched soymilk is an alternative way to reduce LDL-c levels to reduce the risk of cardiovascular disease.

\section{Additional files}

Additional file 1: The difference of percent changes of the total cholesterol, triglyceride, HDL-C and LDL-c levels between groups before and after potential confounders were adjusted $(n=240)$. (DOCX $14 \mathrm{~kb}$ )

Additional file 2: Comparison of fasting plasma glucose level between the study and control groups at weeks $0,2,4,6$ and 8 by Mann-Whitney $U$ test. (DOCX $50 \mathrm{~kb}$ )

Additional file 3: The relative risk of persistent bloating in the study group compared to the control group. (DOCX $17 \mathrm{~kb}$ )

\section{Abbreviations}

LDL-c: Low-density lipoprotein cholesterol; NPC1L1: Niemann-Pick C1-like 1; TG: Triglyceride; HDL-c: High-density lipoprotein cholesterol; VLDL: Very low-density lipoprotein; BMI: Body mass index; WC: Waist circumference; HC: Hip circumference; FPG: Fasting plasma glucose; TC: Total cholesterol; CVD: Cardiovascular diseases; LF/HC: Low-fat, high-carbohydrate; T2DM: Type 2 diabetes mellitus.

\section{Competing interests}

The authors declare that they have no competing interests. 


\section{Authors' contributions}

Noppadol Kietsiriroje had the primary responsibility for the study design, data collection, supervision and execution of the study and wrote the manuscript. Jirateep Kwankaew was a co-investigator who contributed in parts of the proposal preparation and study design and was partly involved in the manuscript preparation. Sunita Kitpakornsanti was a co-investigator who contributed in parts of the proposal preparation and the data collection. Rattana Leelawattana was a co-investigator and supervisor of the study who contributed in parts of the proposal and manuscript preparation and data collection. All authors read and approved the final manuscript.

\section{Authors' information}

Noppadol Kietsiriroje and Assoc. Prof. Rattana Leelawattana. Endocrinologists. Academic instructors in Division of Endocrinology and Metabolism, Department of Internal Medicine, Faculty of Medicine, Prince of Songkla University.

Jirateep Kwankaew. Endocrinologist. Doctor at Samitivej Srinakarin hospital. Former academic instructor in Division of Endocrinology and Metabolism, Department of Internal Medicine, Faculty of Medicine, Prince of Songkla University.

Sunita Kitpakornsanti. Endocrinologist. Doctor at Trang hospital. Former clinical fellowship in Division of Endocrinology and Metabolism, Department of Internal Medicine, Faculty of Medicine, Prince of Songkla University.

\section{Acknowledgement}

The authors are grateful to Rattana Leenum and Nirun Intarut for the statistical analysis and Glenn Shingledecker in the International Affairs Office for proofreading the English.

\section{Financial support}

This study was supported by research funds from Dairy Plus Company Limited.

\section{Author details}

'Division of Endocrinology and Metabolism, Department of Internal Medicine, Faculty of Medicine, Prince of Songkla University, 15 Kanjanavanish Rd, Hat Yai, Songkhla 90110, Thailand. ${ }^{2}$ Internal Medicine Clinic, Samitivej Srinakarin Hospital, Bangkok 10250, Thailand. ${ }^{3}$ Division of Internal Medicine, Trang Hospital, Trang 92000, Thailand.

\section{Received: 24 June 2015 Accepted: 3 November 2015}

Published online: 09 November 2015

\section{References}

1. Executive Summary of The Third Report of The National Cholesterol Education Program (NCEP) Expert Panel on Detection, Evaluation, And Treatment of High Blood Cholesterol In Adults (Adult Treatment Panel III). JAMA. 2001;285(19):2486-97.

2. Calpe-Berdiel L, Escola-Gil JC, Blanco-Vaca F. New insights into the molecular actions of plant sterols and stanols in cholesterol metabolism. Atherosclerosis. 2009;203(1):18-31.

3. Reiner Z, Catapano AL, De Backer G, Graham I, Taskinen MR, Wiklund O, et al. ESC/EAS Guidelines for the management of dyslipidaemias: the Task Force for the management of dyslipidaemias of the European Society of Cardiology (ESC) and the European Atherosclerosis Society (EAS). Eur Heart J. 2011:32(14):1769-818.

4. Jellinger PS, Smith DA, Mehta AE, Ganda O, Handelsman Y, Rodbard HW, et al. American Association of Clinical Endocrinologists' Guidelines for Management of Dyslipidemia and Prevention of Atherosclerosis: executive summary. Endocr Pract. 2012;18(2):269-93.

5. Weihrauch JL, Gardner JM. Sterol content of foods of plant origin. J Am Diet Assoc. 1978;73(1):39-47.

6. Katan MB, Grundy SM, Jones P, Law M, Miettinen T, Paoletti R. Efficacy and safety of plant stanols and sterols in the management of blood cholesterol levels. Mayo Clin Proc. 2003;78(8):965-78.

7. von Bergmann K, Sudhop T, Lutjohann D. Cholesterol and plant sterol absorption: recent insights. Am J Cardiol. 2005:96(1A):10D-4D.

8. Neil HA, Meijer GW, Roe LS. Randomised controlled trial of use by hypercholesterolaemic patients of a vegetable oil sterol-enriched fat spread. Atherosclerosis. 2001;156(2):329-37.
9. Simons LA. Additive effect of plant sterol-ester margarine and cerivastatin in lowering low-density lipoprotein cholesterol in primary hypercholesterolemia. Am J Cardiol. 2002;90(7):737-40.

10. Demonty I, Ras RT, van der Knaap HC, Duchateau GS, Meijer L, Zock PL, et al. Continuous dose-response relationship of the LDL-cholesterollowering effect of phytosterol intake. J Nutr. 2009:139(2):271-84.

11. Maki KC, Lawless AL, Reeves MS, Dicklin MR, Jenks BH, Shneyvas E, et al. Lipid-altering effects of a dietary supplement tablet containing free plant sterols and stanols in men and women with primary hypercholesterolaemia: a randomized, placebo-controlled crossover trial. Int J Food Sci Nutr. 2012;63(4):476-82

12. Criqui MH, Heiss G, Cohn R, Cowan LD, Suchindran CM, Bangdiwala S, et al. Plasma triglyceride level and mortality from coronary heart disease. N Engl J Med. 1993;328(17):1220-5.

13. Laakso M, Lehto S, Penttila I, Pyorala K. Lipids and lipoproteins predicting coronary heart disease mortality and morbidity in patients with non-insulin-dependent diabetes. Circulation. 1993;88(4 Pt 1):1421-30.

14. Fontbonne A, Eschwege E, Cambien F, Richard JL, Ducimetiere P, Thibult N, et al. Hypertriglyceridaemia as a risk factor of coronary heart disease mortality in subjects with impaired glucose tolerance or diabetes. Results from the 11-year follow-up of the Paris Prospective Study. Diabetologia. 1989;32(5):300-4.

15. Jacobson TA, Ito MK, Maki KC, Orringer CE, Bays HE, Jones PH, et al. National lipid association recommendations for patient-centered management of dyslipidemia: part 1-full report. J Clin Lipidol. 2015;9(2):129-69.

16. Aparecida Dos Reis S, Lopes da Conceicao L, Diniz Rosa D, Dos Santos Dias MM, Gouveia Peluzio MD. Mechanisms Used by Inulin-Type Fructans to Improve the Lipid Profile. Nutricion hospitalaria. 2014;31(n02):528-34

17. Letexier D, Diraison F, Beylot M. Addition of inulin to a moderately highcarbohydrate diet reduces hepatic lipogenesis and plasma triacylglycerol concentrations in humans. Am J Clin Nutr. 2003;77(3):559-64.

18. Brighenti F. Dietary fructans and serum triacylglycerols: a meta-analysis of randomized controlled trials. J Nutr. 2007;137(11 Suppl):2552S-6S.

19. Williams CM, Jackson KG. Inulin and oligofructose: effects on lipid metabolism from human studies. Br J Nutr. 2002;87 Suppl 2:S261-4.

20. Weidner C, Krempf M, Bard JM, Cazaubiel M, Bell D. Cholesterol lowering effect of a soy drink enriched with plant sterols in a French population with moderate hypercholesterolemia. Lipids Health Dis. 2008;7:35.

21. Lee $\mathrm{PH}$. Is a cutoff of $10 \%$ appropriate for the change-in-estimate criterion of confounder identification? J Epidemiol. 2014;24(2):161-7.

22. Kriengsinyos W, Sumriddetchkajorn K, Yamborisut U. Reduction of LDL-cholesterol in mildly hypercholesterolemic Thais with plant stanol ester-fortified soy milk. J Med Assoc Thai. 2011:94(11):1327-36.

23. Abumweis SS, Barake R, Jones PJ. Plant sterols/stanols as cholesterol lowering agents: A meta-analysis of randomized controlled trials. Food Nutr Res. 2008;52

24. Cater NB, Garcia-Garcia AB, Vega GL, Grundy SM. Responsiveness of plasma lipids and lipoproteins to plant stanol esters. Am J Cardiol. 2005:96(1A):23D-8D.

25. Anderson JW, Bush HM. Soy protein effects on serum lipoproteins: a quality assessment and meta-analysis of randomized, controlled studies. J Am Coll Nutr. 2011;30(2):79-91.

26. Harland JI, Haffner TA. Systematic review, meta-analysis and regression of randomised controlled trials reporting an association between an intake of circa $25 \mathrm{~g}$ soya protein per day and blood cholesterol. Atherosclerosis. 2008;200(1):13-27.

27. Korpela R, Tuomilehto J, Hogstrom P, Seppo L, Piironen V, Salo-Vaananen P, et al. Safety aspects and cholesterol-lowering efficacy of low fat dairy products containing plant sterols. Eur J Clin Nutr. 2006;60(5):633-42.

28. Volpe R, Niittynen L, Korpela R, Sirtori C, Bucci A, Fraone N, et al. Effects of yoghurt enriched with plant sterols on serum lipids in patients with moderate hypercholesterolaemia. Br J Nutr. 2001:86(2):233-9.

29. Clifton PM, Noakes M, Sullivan D, Erichsen N, Ross D, Annison G, et al. Cholesterol-lowering effects of plant sterol esters differ in milk, yoghurt, bread and cereal. Eur J Clin Nutr. 2004;58(3):503-9.

30. Plana N, Nicolle C, Ferre R, Camps J, Cos R, Villoria J, et al. Plant sterol-enriched fermented milk enhances the attainment of LDL-cholesterol goal in hypercholesterolemic subjects. Eur J Nutr. 2008;47(1):32-9.

31. Devaraj S, Jialal I, Vega-Lopez S. Plant sterol-fortified orange juice effectively lowers cholesterol levels in mildly hypercholesterolemic healthy individuals. Arterioscler Thromb Vasc Biol. 2004;24(3):e25-8. 
32. Rideout TC, Chan YM, Harding SV, Jones PJ. Low and moderate-fat plant sterol fortified soymilk in modulation of plasma lipids and cholesterol kinetics in subjects with normal to high cholesterol concentrations: report on two randomized crossover studies. Lipids Health Dis. 2009:8:45.

33. Grundy SM, Cleeman Jl, Merz CN, Brewer Jr HB, Clark LT, Hunninghake DB, et al. Implications of recent clinical trials for the National Cholesterol Education Program Adult Treatment Panel III guidelines. Arterioscler Thromb Vasc Biol. 2004;24(8):e149-61.

34. Scholle JM, Baker WL, Talati R, Coleman Cl. The effect of adding plant sterols or stanols to statin therapy in hypercholesterolemic patients: systematic review and meta-analysis. J Am Coll Nutr. 2009;28(5):517-24.

35. Parks EJ. Effect of dietary carbohydrate on triglyceride metabolism in humans. J Nutr. 2001:131(10):2772S-4S.

36. Parks EJ, Krauss RM, Christiansen MP, Neese RA, Hellerstein MK. Effects of a low-fat, high-carbohydrate diet on VLDL-triglyceride assembly, production, and clearance. J Clin Invest. 1999;104(8):1087-96.

37. Jackson KG, Taylor GR, Clohessy AM, Williams CM. The effect of the daily intake of inulin on fasting lipid, insulin and glucose concentrations in middle-aged men and women. Br J Nutr. 1999;82(1):23-30.

38. Carabin IG, Flamm WG. Evaluation of safety of inulin and oligofructose as dietary fiber. Regul Toxicol Pharmacol. 1999;30(3):268-82

\section{Submit your next manuscript to BioMed Central and take full advantage of:}

- Convenient online submission

- Thorough peer review

- No space constraints or color figure charges

- Immediate publication on acceptance

- Inclusion in PubMed, CAS, Scopus and Google Scholar

- Research which is freely available for redistribution 